\title{
Elastic tests on a model of the Oldbury nuclear station prestressed concrete pressure vessel
}

by

\author{
I. W. Hornby, B.Sc.(Eng.), A.M.I.C.E., G. F. Verdon, B.Sc.(Eng.) \\ and \\ Y. C. Wong, B.Sc.(Eng.), A.M.I.Mech.E.
}

Professor A. L. L. Baker (Department of Civil Engineering, Imperial College) wrote that the Authors had reported good agreement between calculated and measured strains due to pressure acting on the uncracked vessel. This was valuable and important, but other results would be of even greater interest, e.g. those obtained for "pressure and thermal tests at operating conditions, including prolonged loading for measuring creep effects', as mentioned in $\S 3(b)$. Perhaps these could be reported later.

67. Professor Baker wished to put the following questions to the Authors.

(a) At what rate of heating and at what temperature gradient combined with pressure could cracking occur at first heating, and also at what pressure after a long period of working followed by cooling and rapid re-pressurizing without fully heating?

(b) What was the possible influence on the safety factor against failure by shear combined with tension in the top slab of cracking at mid-span outside, and at the corners inside? Outside mid-span cracking might be started by excessive bending and temperature gradient combined with loss of prestress due to creep and shrinkage of the concrete. Cracking in the inside corner might be started by re-pressurization following cooling after a period of operation resulting in residual compressive strains due to creep and shrinkage under heat.

68. The computer calculations were impressive, but the concrete compressive stresses throughout most of the vessel reduced as pressure rose. Safety in regard to concrete would mainly depend on the long-term strength of the concrete immediately supporting anchorages, where local stresses increased as pressure rose when cables were not bonded. The shear strength of the end slabs might also be critical.

The Authors, in reply, thanked Professor Baker for his contribution which covered the non-elastic, as well as the elastic, behaviour of the model. They agreed that tests under operating conditions, i.e. under thermal loading and pressure, were of great interest, particularly those carried out over prolonged periods. It was their intention to publish that information later. The questions on the effects of prolonged thermal loading could be answered only when the theoretical work on the approximate creep analysis was complete. They would, therefore, keep their discussion within the scope of the elastic tests reported in the present Paper.

70. The rate at which the vessel was heated up would not affect the maximum tensile stresses; these occurred at steady state. Rapid heating only raised the maximum compressive stresses on the inside surface of the vessel. At the equator of the vessel, the circumferential stress was made up as follows: ( - ve tensile; +ve compressive).

Prestress

Pressure $(350 \mathrm{lb} / \mathrm{sq}$. in.)

Steady-state temperature $\left(55^{\circ} \mathrm{C}\right.$ to $\left.25^{\circ} \mathrm{C}\right)-712 \mathrm{lb} / \mathrm{sq}$. in.

Net stress
$+1436 \mathrm{Ib} / \mathrm{sq}$. in.

$-660 \mathrm{lb} / \mathrm{sq}$. in.

$+64 \mathrm{lb} / \mathrm{sq}$. in. 
If the concrete ultimate tensile strength was $500 \mathrm{lb} / \mathrm{sq}$. in., then the temperature difference would need to be increased to about $62^{\circ} \mathrm{C}$ (say $87^{\circ} \mathrm{C}$ to $25^{\circ} \mathrm{C}$ gradient) before the outside cracked (shrinkage stresses excluded).

71. The influence of cracking of the top slab mid-span and inside corner could not be assessed by elastic analysis alone. It had been proved, however, that cracking of an area of the top slab to $15 \%$ of its depth caused no increase in stresses throughout. Tension at the inside corner, due to residual creep strain developed under normal design stresses, could be avoided, if necessary, by appropriate operating procedures. If residual strains greater than those estimated above were developed, then cracking might result, and a non-linear analysis would be required in assessing its effect on the load factor.

72. The Authors agreed that conerete stresses in anchorage zones were most important and an investigation into their distribution was a research project currently in progress. Although the anchorage stresses in the full-size vessel were not exactly simulated in the model, it was found that the changes in cable loads during pressurization were extremely small. These were just detectable by the load cells, being in the order of 0.04 ton at $442 \mathrm{lb} / \mathrm{sq}$. in. Even during the ultimate test, with a pressure of $1200 \mathrm{lb} / \mathrm{sq}$. in. and the vessel badly cracked, the transfer of load to the cables was less than $8 \%$. 